\title{
Barriers to medical device innovation
}

This article was published in the following Dove Press journal:

Medical Devices: Evidence and Research

13 June 2014

Number of times this article has been viewed

\section{Jacob Bergsland \\ Ole Jakob Elle \\ Erik Fosse}

The Intervention Centre, Oslo University Hospital, Institute of Clinical Medicine, University of Oslo, Oslo, Norway
Correspondence: Jacob Bergsland

The Intervention Centre, Oslo University Hospital, Sognsvannsveien 20, 0424 Oslo, Norway

Tel +479303 I292

Fax +47 23070110

Email jacob.bergsland@ous-hf.no
Abstract: The US Food and Drug Administration (FDA) has defined a medical device as a health care product that does not achieve it's purpose by chemical action or by being metabolized. This means that a vast number of products are considered medical devices. Such devices play an essential role in the practice of medicine. The FDA classifies medical devices in three classes, depending on the risk of the device. Since Class I and II devices have relatively simple requirements for getting to the market, this review will focus on "implantable devices", which, in general, belong to Class III. The European Union and Canada use a slightly different classification system. While early generations of medical devices were introduced without much testing, either technical or clinical, the process of introducing a Class III medical device from concept to clinical practice has become strongly regulated and requires extensive technological and clinical testing. The modern era of implantable medical devices may be considered to have started in the 1920s with development of artificial hips. The implantable pacemaker was another milestone and pacemakers and cardioverters/defibrillators have since saved millions of lives and created commercial giants in the medical device industry. This review will include some examples of cardiovascular devices. Similar considerations apply to the total implantable device market, although clinical and technological applications obviously vary considerably.

Keyword: implantable, FDA, regulation, CE-mark, innovation

\section{Introduction}

The global economy is becoming more interconnected, although huge differences remain between the developed and the developing world. This is observed in all aspects of life, maybe nowhere greater than in medical care, where perinatal mortality, communicable diseases, malnutrition, and other public health issues dominate in poor - and noncommunicable diseases in the richer - countries.

The access to cardiac surgery, a specialty highly dependent on medical devices and technology, can serve as an example of uneven access. In the US, more than 1,000 cardiac procedures per million of population are performed every year. In Africa, the number is 18. Although the demand in Africa is probably lower due to the disease panorama and age composition, the numbers illustrate the enormous difference in treatment availability. The majority of the global population has no access to cardiac surgery or other therapies that require advanced technology and implantable devices. For cardiac pacemakers, close to $70 \%$ of all sales occur in USA and Europe, while large population groups in Africa and Asia have no access. Even in developed countries, penetration of new technology may be slow. A disconnect between the technological and medical communities is common, making translation of scientific discoveries into practical 
medical devices and procedures slower than necessary. Issues related to intellectual property rights (IPRs) are another hurdle. The extensive testing required by the US Food and Drug Administration (FDA) or by European Notified Bodies represents large and risky financial commitments. Even after successful clinical testing, the ultimate financial result of investments may be questionable, since payments for products and services through reimbursement mechanisms are not guaranteed. Reimbursements may require further studies, documenting a favorable cost/benefit analysis for patients, health care providers, or even the society at large. The cost of such studies is often the responsibility of device manufacturers. This article will attempt to give an overview of major barriers to implantable medical device innovation and indicate possibilities for lowering such hurdles.

The following topics will be discussed herein in an attempt to give a comprehensive review:

- medical practice patterns and education;

- market size and penetration;

- research and development (R\&D) and device failures;

- regulatory limitations and approval processes;

- IPRs, patent limitations, and publication issues;

- reimbursements, pricing, and payments; and

- ethical considerations.

\section{Medical practice patterns and education}

Although medical practice is changing rapidly, there is an inherent conservatism in medicine that favors the status quo. ${ }^{1}$ New methods are frequently and often rightly introduced only after controlled studies have been performed and acknowledged by the "medical establishment". For new procedures and technology to become standard of care, randomized studies and meta-analyses are required. Even when such studies are completed, years may pass before a device or procedure is widely utilized. This constitutes a concern for device developers who invest huge resources to get a device to market. The period of high-income potential for the new product may be short, making it less advantageous to be the first out with new technology. The process of introducing new technology in hospitals is often complicated and depends on consensus between physician and administration. ${ }^{2}$

Lack of cooperation and exchange of ideas between medical and engineering communities slows development, although certain major teaching institutions have initiated programs to speed innovation and bring new products to market faster. ${ }^{3}$

\section{Market size and penetration}

The worldwide market for medical implantable devices is increasing, but there exists a severe maldistribution between rich and poor countries. Comparing this situation to the market for consumer technology such as mobile phones, the mismatch becomes obvious and critical. While mobile phones are available for a majority of the world's population, cardiac pacemakers are scarce and it is estimated that 1-2 million patients die every year due to lack of pacemaker and defibrillator therapy. ${ }^{4}$ While an average African can afford a mobile telephone and payment for subscription services, he/she cannot afford a lifesaving pacemaker and fees required for the implantation and follow-up. This can be partly understood as a lack of focus on emerging markets by medical device companies and lack of infrastructure and expertise in the health care systems. Device companies may be reluctant to supply lower priced products for the emerging market, being afraid of cannibalizing their own products and eroding profit margins. Device companies in emerging countries have only to a small degree been able to profit from the lack of conveniently priced products, although some countries, including India ${ }^{5,6}$ and Taiwan, ${ }^{7}$ have developed a viable medical device industry, in part based on reverse engineering of existing products.

\section{R\&D and material failures}

R\&D and marketing of medical devices are ventures of high risk. The process from idea to practical clinical application is long and expensive. Traditionally, early research is performed in academic institutions, while device development, testing, and production occurs in the corporate environment. Processes are costly and frequently take years to accomplish. In spite of extensive testing of products both ex vivo and in vivo, the chance of later failure of new products may cause serious medical problems for the individual and financial disaster for the producer.

Prime examples of failed devices are the Christiansen hip prosthesis ${ }^{8}$ and the Björk-Shiley heart valve, ${ }^{9}$ as well as, recently, silicone breast implants in France. ${ }^{10}$ The potential legal and financial implications of such failures constitute significant risk for investment. The Björk-Shiley valve issue, wherein welded valve struts broke and caused leaflet embolization, ${ }^{11}$ can serve as an example. The manufacturing company went bankrupt due to personal injury claims. The Björk-Shiley experience led to stricter testing procedures and clinical follow-up of heart valve devices, which is of benefit to patients, but serves as a barrier to innovation since new claims can surface more than 20 years after 
implantation of a device. ${ }^{12}$ Initial approval and successful implantation of a device is certainly not a guarantee against later complications. ${ }^{13}$ For the developing world and for poor countries it may be unreasonable to expect the same level of sophistication and safety features of medical devices as those demanded by Western regulative bodies. Gross domestic product of many poor countries cannot support implantation of expensive implantables to the population even for life-threatening disease, and it may be reasonable to allow simpler, maybe even less secure devices, in such markets. At present, only the rich and political leaders in poor countries have access to sophisticated device therapy.

\section{Regulatory issues and approval processes}

Implantable devices represent risks to patients and are classified as Class III devices, ${ }^{14}$ required to undergo premarket approval. ${ }^{15}$ In the US, this process is controlled by the FDA, a government agency. ${ }^{16}$ In Europe, the process is conducted by so-called Notified Bodies, which may be private companies or foundations. The FDA requires evidence of safety and efficacy from new devices, while premarket evaluation in Europe requires proof ${ }^{17}$ of safety. ${ }^{18}$ This has made it somewhat easier to introduce new technology in Europe, although the CE mark process is both less transparent and considered less demanding in proving that a device is truly beneficial. ${ }^{19}$ The process of obtaining approval is significantly longer for new technology than for devices that are similar to existing technology. In USA, most devices go through a $510(\mathrm{k})$ registration, which is used to approve products similar to devices that have already gone through the FDA process. This situation may result in a disincentive to be the "first" in innovating new products, although using the $510(\mathrm{k})$ registration process may compromise IPRs. Efforts are being made to standardize clinical testing to make it more efficacious and less expensive. ${ }^{20}$ Cooperation in the early testing phase between medical device competitors may decrease cost and release government resources when it comes to what is considered essential new developments. ${ }^{21}$

\section{IPRs, patent issues, and publication}

New medical devices are frequently a result of cooperation between academia and commercial interests. This may cause conflicts between the wish to publish and the interest in patenting and acquiring IPRs. ${ }^{22}$ Previously, the IPRs of academicians and hospital employees may have been poorly protected, leaving the researcher with the option to keep an innovation secret or publish it, risking loss of protection by the latter.
Technology transfer organizations are facilitating cooperation between corporations and universities, thereby lowering this barrier. Small companies, developing innovative devices, may be in an unfavorable position to protect their IPR against corporations with vast legal and financial resources. Big corporations frequently cover their products by wide and general patents, preventing new innovation. Physicians are important contributors to device innovation ${ }^{23,24}$ and inadequate IPR regulations may present another barrier to innovative development unless technology transfer organizations actively assist in protecting IPRs.

The issue of patent legislation and practice may be a double-edged sword. Obtaining a patent may encourage innovation by giving patented product exclusivity for the time of the patent duration. On the other hand, patents significantly increase the price of devices and may decrease innovative efforts in the corresponding field. Gold et al give a thoughtful analysis of the value and limitations of the present practices of patent legislation. ${ }^{25}$ The market restrictions in the developing world to modern device or pharmaceutical therapy is a particularly serious issue. ${ }^{25}$ Alternatives to the present patent practice have been suggested. ${ }^{26}$

\section{Reimbursement and pricing}

Payment for medical services is in many countries based on diagnosis-related grouping ${ }^{27}$ and may not include the cost of new innovative devices. Procedures involving new devices may represent a financial strain or loss for the health care providers. This has been demonstrated for cochlear implants ${ }^{27}$ and was recently demonstrated to be an important issue for transcatheter aortic valve implantation. ${ }^{28}$ The lack of payments for innovative technology may impair the introduction of new technology and thereby innovation of devices. ${ }^{29}$ The legislation in different countries may vary significantly, ${ }^{30}$ and the lack of predictability is an obvious barrier to innovation.

In emerging markets, limited payment ability seriously hinders introduction of new technology and makes innovation in the device market particularly difficult for domestic companies. ${ }^{31}$ As mentioned earlier, the patent legislation may further impede development in low-income countries, although such countries could utilize reverse engineering practice and produce out-of-patent devices. Health technology assessment studies now frequently include cost-efficiency analysis. The outcomes of such studies may discourage health care providers from introducing more costly technology, if they do not demonstrate significant clinical advantages. ${ }^{32}$ This introduces additional risk for innovative technology developers. ${ }^{1-3}$ 


\section{Ethical considerations}

Health care access is considered a human right by the World Health Organization, ${ }^{33}$ but, for the majority of the global population, this right remains an illusion. ${ }^{34}$ Although the health challenges are different, the richest countries also struggle with distribution and access to care. Transplantation and use of life-support technology such as dialysis and circulatory assist devices, in principle, should be available for everybody in need, ${ }^{35}$ but access is, in reality, severely limited globally. ${ }^{36}$ This demonstrates ethical dilemmas applicable for expensive implantable devices as well. ${ }^{37}$ In many countries, life-supporting devices such as pacemakers may not be covered by insurance, and therapy thereby restricted on financial rather than medical indications. Even worse, in some countries, corruptive practices within the health care system serve as the allocation system for expensive technological and device-dependent therapies. Corruption can drastically increase device prices, thereby restricting access and subsequently reducing profitability and market penetration for the device manufacturers.

\section{Conclusion}

Medical device innovation has brought huge benefits to patients, especially in the developed world, while the population in developing and poor countries have experienced much fewer benefits. Development and diffusion of innovative medical devices has been slower than for certain consumer products due to the barriers to innovation. Although some of the barriers are necessary and must remain in place due to patient safety and definition of device efficacy, other barriers could be removed or made lower by improved policies and closer cooperation between various stakeholders.

Integration of medical and technological expertise may result in more rapid and focused development and, thereby, increased availability of investment capital. Early R\&D may occur through consortia including academia, industry, and government agency, thereby decreasing investor risk aversion. Streamlining of clinical testing, including a more standardized approach to the health technology assessment process, may speed up introduction and diffusion of cost-effective devices. Changes in patent laws and the way such laws are practiced may decrease cost and increase competition. Although lowered prices may challenge the present business model for device companies, increased sales could compensate them financially by the creation of a true global market. The sometimes excessive pricing of medical devices is probably unsustainable both in the rich and the low-to-middle income parts of the world. Many lifesaving medical devices have the potential to become reasonably priced mass-produced products. For the medical profession, such development would make it easier to adhere to its basic ethical principles when working with medical technology. ${ }^{38}$

\section{Disclosure}

The authors report no conflicts of interest in this work.

\section{References}

1. Forman R. Medical resistance to innovation. Med Hypotheses. 1981;7(8):1009-1017.

2. Greer AL. Rationing medical technology. Hospital decision making in the United States and England. Int J Technol Assess Health Care. 1987;3(2):199-221.

3. Yazdi Y, Acharya S. A new model for graduate education and innovation in medical technology. Ann Biomed Eng. 2013;41(9): 1822-1833

4. Ochasi A, and Clark P. Reuse of pacemakers in Ghana and Nigeria: medical, legal, cultural and ethical perspectives. Developing world bioethics. Epub 2014 Apr.

5. Mahal A, Karan AK. Diffusion of medical technology: medical devices in India. Expert Rev Med Devices. 2009;6(2):197-205.

6. Jarosławski S, Saberwal G. Case studies of innovative medical device companies from India: barriers and enablers to development. $B M C$ Health Serv Res. 2013;13:199.

7. Qian KX. One thousand dollar assist heart pump for patients from developing countries. Open Biomed Eng J. 2007;1:11-12.

8. Ohlin A. Failure of the Christiansen hip. Survival analysis of 265 cases. Acta Orthop Scand. 1990;61(1):7-11.

9. Harrison DC, Ibrahim MA, Weyman AE, Kuller LH, Blot WJ, Miller DE. The Björk-Shiley convexo-concave heart valve experience from the perspective of the supervisory panel. Am J Cardiol. 2013;112(12): 1921-1931.

10. Reyal F, Feron JG, Leman Detour S, et al. The impact of poly implant prothèse fraud on breast cancer patients: a report by the institut curie. Plast Reconstr Surg. 2013;131(4):690-695.

11. Davis PK, Myers JL, Pennock JL, Thiele BL. Strut fracture and disc embolization in Björk-Shiley mitral valve prostheses: diagnosis and management. Ann Thorac Surg. 1985;40(1):65-68.

12. Blot WJ, Ibrahim MA, Ivey TD, et al. Twenty-five-year experience with the Björk-Shiley convexoconcave heart valve: a continuing clinical concern. Circulation. 2005;111(21):2850-2857.

13. Bergsland J, Hol PK, Lingås PS, et al. Intraoperative and intermediateterm angiographic results of coronary artery bypass surgery with symmetry proximal anastomotic device. J Thorac Cardiovasc Surg. 2004;128(5):718-723.

14. van Eck CF, Chen AF, Klatt BA, D'Antonio J, Fu F. The classification of implants: class I, II, III. J Long Term Eff Med Implants. 2009;19(3): 185-193.

15. Ramsey SD, Luce BR, Deyo R, Franklin G. The limited state of technology assessment for medical devices: facing the issues. Am J Manag Care. 1998;4 Spec No:SP188-SP199.

16. Chen EA, Patel-Raman SM, O'Callaghan K, Hillebrenner MG. FDA's perspectives on cardiovascular devices. J Cardiovasc Transl Res. 2009;2(2):143-146.

17. Crisp S. The medical device directives and their impact on the development and manufacturing of medical implants. Proc Inst Mech Eng H. 1996;210(4):233-239.

18. Vinck I, Hulstaert F, Van Brabandt H, Neyt M, Stordeur S. Market introduction of innovative high risk medical devices: towards a recast of the directive concerning medical devices. Eur J Health Law. 2011;18(5): $477-489$. 
19. Hulstaert F, Neyt M, Vinck I, et al. Pre-market clinical evaluations of innovative high-risk medical devices in Europe. Int J Technol Assess Health Care. 2012;28(3):278-284.

20. Krucoff MW, Brindis RG, Hodgson PK, Mack MJ, Holmes DR Jr. Medical device innovation: prospective solutions for an ecosystem in crisis. Adding a professional society perspective. JACC Cardiovasc Interv. 2012;5(7):790-796.

21. Goodman CS, Gelijns AC. The changing environment for technological innovation in health care. Baxter Health Policy Rev. 1996;2:267-315.

22. Blumenthal D, Causino N, Campbell E, Louis KS. Relationships between academic institutions and industry in the life sciences - an industry survey. N Engl J Med. 1996;334(6):368-373.

23. Chatterji AK, Fabrizio KR, Mitchell W, Schulman KA. Physicianindustry cooperation in the medical device industry. Health Aff (Millwood). 2008;27(6):1532-1543.

24. Smith SW, Sfekas A. How much do physician-entrepreneurs contribute to new medical devices? Med Care. 2013;51(5):461-467.

25. Gold ER, Kaplan W, Orbinski J, Harland-Logan S, N-Marandi S. Are patents impeding medical care and innovation? PLoS Med. 2010;7(1): e1000208.

26. Hynek P. The Hyper-Commons: how open science prizes can expand and level the medical research playing field. Rejuvenation Res. 2008;11(6):1065-1072.

27. Kane NM, Manoukian PD. The effect of the Medicare prospective payment system on the adoption of new technology. The case of cochlear implants. N Engl J Med. 1989;321(20):1378-1383.

28. Dahle G, Rein KA, Fiane A, et al. Innovative technology-transcatheter aortic valve implantation: cost and reimbursement issues. Scand Cardiovasc J. 2012;46(6):345-352.
29. Everard ML. The Emperor's New Clothes II - time for regulators to wake up and take responsibility for unnecessary asthma morbidity: time for the second aerosol 'transition'. Thorax. 2013;68(9):891-893.

30. Scheller-Kreinsen D, Quentin W, Busse R. DRG-based hospital payment systems and technological innovation in 12 European countries. Value Health. 2011;14(8):1166-1172.

31. Jones Z, Woods E, Nielson D, Mahadevan SV. Design of a pulse oximeter for price sensitive emerging markets. Conf Proc IEEE Eng Med Biol Soc. 2010;2010:1085-1088.

32. Ligthart S, Vlemmix F, Dendukuri N, Brophy JM. The cost-effectiveness of drug-eluting stents: a systematic review. CMAJ. 2007;176(2):199-205.

33. Schrecker T, Chapman AR, Labonté R, De Vogli R. Advancing health equity in the global marketplace: how human rights can help. Soc Sci Med. 2010;71(8):1520-1526.

34. Rennie S, Mupenda B. Living apart together: reflections on bioethics, global inequality and social justice. Philos Ethics Humanit Med. 2008;3:25

35. Garcia GG, Harden P, Chapman J; World Kidney Day Steering Committee 2012. The global role of kidney transplantation. Transplantation. 2012;93(4):337-341.

36. McQueen KA, Ozgediz D, Riviello R, et al. Essential surgery: integral to the right to health. Health Hum Rights. 2010;12(1):137-152.

37. Argenziano M, DeRose JJ, Oz MC, Rose EA. Treatment of endstage heart disease with mechanical circulatory assistance. Jpn Circ J. 1997;61(11):887-892.

38. Kapp MB. Life-sustaining technologies: value issues. J Soc Issues. 1993;49(2):151-167.
Medical Devices: Evidence and Research

\section{Publish your work in this journal}

Medical Devices: Evidence and Research is an international, peerreviewed, open access journal that focuses on the evidence, technology, research, and expert opinion supporting the use and application of medical devices in the diagnosis, treatment and management of clinical conditions and physiological processes. The identification of novel

\section{Dovepress}

devices and optimal use of existing devices which will lead to improved clinical outcomes and more effective patient management and safety is a key feature. The manuscript management system is completely online and includes a quick and fair peer-review system. Visit http://www. dovepress.com/testimonials.php to read real quotes from authors. 